\title{
Social Consequences of Economy Digital Transformation
}

\author{
Elena Ivushkina, Natalia Alieva, Nelli Morozova*
}

\author{
Institute of Service and Business (branch) of DSTU in Shakhty, Rostov, Russia
}

*Corresponding author.Email: morozova-nelli-86@yandex.ru

\begin{abstract}
Today, digital transformation is bringing an era of change. The world is changing as a result of digital transformation, introducing modern digital technologies into our lives As a result of the introduction of digital technologies, all spheres of life and production are changing: in the sphere of economic relations, a digital economy is emerging, in the sphere of interaction between society and the state - a digital government, in the sphere of high - tech infrastructure - a digital space, in the sphere of state development-a digital society. Digital transformation relies on the automation of all business processes, has an impact on human relationships and individual behavior. At the same time, digital transformation can lead to serious social consequences, such as increased unemployment, reduced labor force, the disappearance of companies, cybercrime, social anomie, and so on.
\end{abstract}

Keywords: digital economy, transformation, social consequences.

\section{INTRODUCTION}

Digitalization of modern life is becoming a global reality. By 2024, the Russian state plans to carry out digital transformation of all spheres of activity and social life of the state. The implementation of this project is based on the development and approval of a legislative framework in the field of digital technologies, modernization of the existing digital infrastructure, and the introduction of digital practices in all sectors of the economy and public administration, as well as training personnel for the transition period. Digital transformation refers to the introduction of digital technologies in production and business activities, the infrastructure of public relations, which requires fundamental changes in all areas of activity: technology, culture, production, etc. Adopted in Russia in 2017, the program "Digital Economy of the Russian Federation" (Russian Government Order of 28.07.2017 No. 1632-r) represents the beginning of digitalization based on digital technologies, the introduction of which will bring changes to production and human life. Federal projects (figure) have been identified to manage the program.

Such digital transformation, based on innovation, is associated with the use of its results both in professional activities and in the ordinary life of citizens. Digital transformation is happening in every area:
- in economic relations in the form of a digital economy;

- in society and the state - in the form of digital government;

- in a high-tech infrastructure in the form of a digital space, in the development of a state in the form of a digital society.

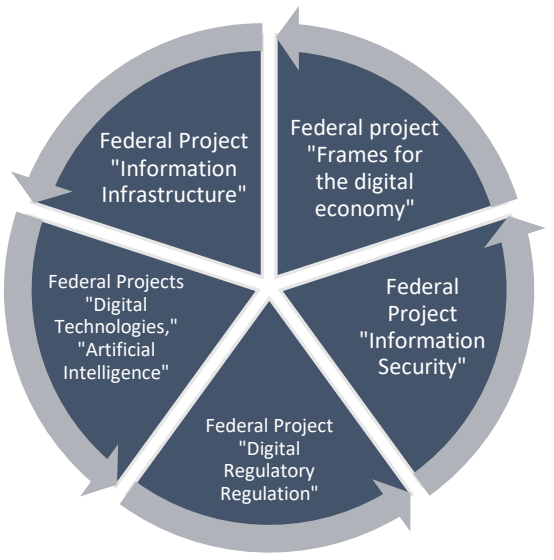

Figure 1 Directions of the National Digital Economy Program

In general, the concept of digital transformation is represented by the integration of technological processes and processes of the infrastructure of public relations, which radically changes our world with new technologies and culture. Digitalization is called a global revision of 
approaches and strategies in production, business, society based on information technology [1]. The term "digitalization" was introduced by the American computer scientist Nicholas Negroponte in 1995 in the book «Being Digital». The term "digitalization" has two meanings: narrow and broad. The narrow meaning of digitalization is a process that converts information into digital form, reducing costs and bringing new opportunities.

The broad meaning of digitalization is represented by its new system of relations - economic, social, and cultural, which are based on information and communication technologies. Digital information is penetrating into all spheres of society, becoming a driver of world development. The ongoing digital transformation comes down not only to production, business, science, but also to the social sphere. Users of digital information are both specialists and ordinary citizens.

Digital transformation is transferring our world to the sixth technological order and the fourth industrial revolution (Industry 4.0) [2, 3]. The fourth industrial revolution could lead the world to a technological singularity - the point at which technology will become inaccessible to humans due to the complexity of technology.

Despite the colossal possibilities of digitalization processes for the development of the economy and other areas, there are social risks and threats. And also digitalization brings challenges to the Russian economy that affect the problems of national security and the competitiveness of products in the world market. The question of how exactly digital training should be carried out remains open.

\section{THEORETICAL BASIS OF THE RESEARCH}

The digital economy and digitalization of modern life are becoming a global reality. The Davos Forum of 2015 proclaimed the beginning of the Fourth Industrial Revolution, characterized by a mixture of physical, digital and biological technologies. In 2017, the Government of the Russian Federation developed and approved the "Strategies for the Development of the Information Society in the Russian Federation for 20172030" (Decree No. 203 of the President of the Russian Federation on 09.05.2017). In this program, the digital economy is understood as "an economic activity in which the key factor of production is digital data, processing of large volumes and the use of analysis results, which, in comparison with traditional forms of management, can significantly increase the efficiency of various types of production, technologies, equipment, storage, sales, delivery of goods and services".
The proposed Strategy presents digitalization as the basis for a new transformation, which is necessary for the development of the entire economy and society. The task of digitalization is to create a digital space that will allow satisfying the needs of society in obtaining reliable information, developing the infrastructures of the Russian Federation, creating Russian information and telecommunication technologies, and, as a result, constructing a new technological basis for the social and economic sphere. At the same time, the digital economy introduces social problems: the acceleration of life pace, an increase of information volume, the complication of socio-economic conditions, and constant psychoemotional stress. In the sphere of society, new problems of the unemployment risk, social stratification, the intensive introduction of informatization leads to stressful situations and negative consequences for the workers' health.

The contradictory impact of the digital economy on the socio-economic development of countries is revealed. On the one hand, the widespread use of digital technologies can increase labor productivity, reduce costs and create new jobs. On the other hand, the digitalization of the economy in the context of globalization generates negative socio-economic consequences and risks, which are manifested in the reduction of the working population, the monopolization of markets and the weakening of competition, in the strengthening of uneven economic development between countries, and the strengthening of inequality in the distribution of income. To mitigate the negative consequences of digitalization, it is necessary to take appropriate measures from the state.

Consider the negative socio-economic consequences of the digital economy. There is an impossibility of anonymity due to the digital traces left by each person, which makes it possible to track any of his activities [4, 5] There is a transformation of the labor market due to the automation of the routine activities of financial specialists, auditors, accountants, who will be replaced by algorithms and machines. As a result of this process, there is a significant undermining of the material wealth of employees who make up the large middle class.

Moreover, the Russian educational project "Atlas of New Professions" has already been developed, which presents professions that will disappear before 2030 . These include intellectual professions, such as accountant, librarian, legal adviser, notary, journalist, translator, etc. In the working professions, the dispatcher, janitor, elevator operator, postman, freight train driver, security guard, miner, seamstress, dry cleaner, waiter, etc. will disappear.

The disappearance of professions will worsen the financial and social situation of the middle class, and political systems and social relations will be imbalanced. All this leads to the formation of uncertainty on a global 
scale, intensifies social unrest and, as a result, creates dramatic changes in the structure of society. Such dramatic changes include the replacement of humans with robots in most areas of activity in order to save costs for large businesses. For the remaining knowledge workers and operator professions, digital technologies are changing the priorities of professional activities in the form of expanding their range.

The solution of the presented tasks offers long life education, which is necessary for a person to independent track the competencies that he needs at this stage, and master them. Finding a person in a state of continuous education and development is necessary for the maintenance of traditional and creation of new professions. Moreover, the speed of the ongoing changes will be increased.

The creators of the "Atlas of New Professions" project believe that first of all, they need additional professional skills in the form of system thinking, interindustry communication skills, management skills, programming, as well as skills of customer orientation, multiculturalism, multilingualism, sociability, multifunctionality, creativity. Forecasts of professions requested until 2030 include: IT medic, medical robot operator, healthcare manager, personal security designer, creative states coach, ecopropologist, online educational platform coordinator, virtual worlds designer, builder, living systems architect, robotic systems engineer, multicurrency translator, virtual lawyer, IT preacher, home robot designer, city farmer, etc. The table shows a set of supra-professional skills in the professions of the future (using the example of education).

The list of new professions expected in Russia includes the appearance of 186 names. Despite the mystery and improbability of the presented professions, they are already used in robotic industries, medicine based on robot surgeons, stock trading, in agriculture in the form of unmanned harvesters, in the military in the form of drones against terrorists.

Thus, digitalization introduces income inequality, undermines the economy of a number of countries, increases social instability, and mass unemployment. The problem of forming digital economy in Russia passes not only into the problems of competitiveness in the world market in the form of external challenges, but also into the national problems of training and employment of digital personnel at the current stage of the development of the digital economy [6]. Digitalization can change our society much sooner than the skeptics assume now. For example, robotization will lead to massive job cuts in the nearest future.

\section{METHODS AND SUBJECT BASE OF THE STUDY}

The emergence of digitalization and digital transformation introduced a number of new theoretical and methodological problems that were not included in a number of economic and social areas, which caused the actualization of our research in the context of the challenges of our time. Digital transformation needs a

Table 1. Over-professional skills in the professions of the future on the example of the education sector.

\begin{tabular}{|c|c|c|c|c|c|c|c|c|c|c|c|}
\hline $\begin{array}{l}\text { Professions / Over- } \\
\text { professional skills }\end{array}$ & 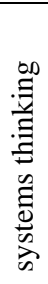 & 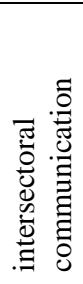 & 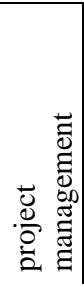 & 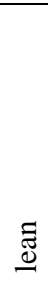 & 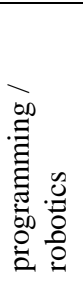 & 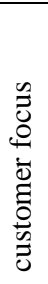 & 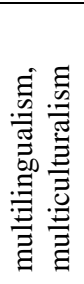 & 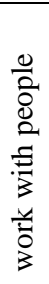 & 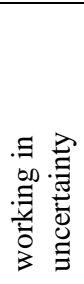 & 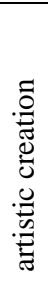 & 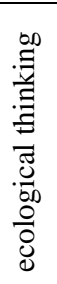 \\
\hline Moderator & $\mathrm{V}$ & $\mathrm{V}$ & $\mathrm{V}$ & & & & & $\mathrm{V}$ & & $\mathrm{V}$ & \\
\hline $\begin{array}{l}\text { Educational trajectory } \\
\text { developer }\end{array}$ & $V$ & $\mathrm{~V}$ & V & & $\mathrm{V}$ & $\mathrm{V}$ & & $\mathrm{V}$ & & $\mathrm{v}$ & \\
\hline Tutor & $\mathrm{V}$ & $\mathrm{V}$ & $\mathrm{v}$ & & & $\mathrm{V}$ & & $\mathrm{v}$ & & & \\
\hline Project training organizer & V & 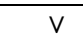 & V & & & 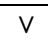 & & V & & $\mathrm{v}$ & \\
\hline $\begin{array}{l}\text { Online educational platform } \\
\text { coordinator }\end{array}$ & $\mathrm{V}$ & $\mathrm{v}$ & $\mathrm{V}$ & & $\mathrm{V}$ & & $\mathrm{V}$ & $\mathrm{V}$ & & & \\
\hline Startup mentor & $\mathrm{V}$ & $\mathrm{V}$ & $\mathrm{V}$ & & $\mathrm{V}$ & $\mathrm{V}$ & $\mathrm{V}$ & & & & \\
\hline Eco-preacher & $\mathrm{v}$ & $\mathrm{V}$ & $\mathrm{V}$ & & & & & $\mathrm{V}$ & & & $\mathrm{v}$ \\
\hline Igromaster & V & V & & & & & V & $\mathrm{V}$ & & $\mathrm{V}$ & \\
\hline Game teacher & $\mathrm{V}$ & $\mathrm{V}$ & & & & & V & $\mathrm{V}$ & & $\mathrm{V}$ & \\
\hline Mind fitness trainer & V & $\mathrm{V}$ & $\mathrm{V}$ & & $\vee$ & $\mathrm{V}$ & & $\mathrm{V}$ & & & \\
\hline $\begin{array}{l}\text { Developer of tools for } \\
\text { learning states of awareness }\end{array}$ & $\mathrm{V}$ & $\mathrm{V}$ & V & & 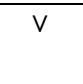 & V & & V & & & \\
\hline
\end{tabular}


new research methodology with the involvement of a new conceptual apparatus and methodological tools. Our study examines a new object - digital transformation, as well as the accompanying phenomena in the form of social consequences, social adaptation, and digital personnel.

Methodology as a logical organization of digital transformation is to determine the purpose and subject of digital transformation research, to find approaches and guidelines to the problem, to choose methods of digital transformation.

Digital transformation is presented as a new object of the social sphere in the form of research and a new direction that needs fundamental study. This is due to the ambiguity of the concept of "digital transformation", the lack of study. Modernity requires clarification and development of the concepts of "digital transformation", "social consequences of digital transformation", corresponding to their new understanding. Moreover, the use of the concept of "digital transformation" should be considered from different angles: production, technological, economic, social, and others.

The multiplicity and broad scale of digital transformation requires new research and new approaches. The first approach to the study of digital transformation is to consider social approaches in the form of digitalization in the life of a person, society, and economy. The second approach, the security of digital transformation, considers its risks and dangers as a set of problems that arise and already exist for risky areas.

Digitalization in human life makes it necessary to study the social consequences of digital transformation, as digital technologies affect human life. The digital age and the technology transform the labor market. The new specialists should be digital staff. This means that they must be ready for changes, continuous training, meet the requirements of professional competencies and their continuous change. There is a need to master new professions and modernize old ones $[6,7]$.

Digitalization of the individual is associated with the creation of a system that tracks each citizen, and constantly and in real time [8]. Such a tracking system distributes social benefits. Citizens who enjoy the trust of the state receive benefits, while citizens with a low rating have restrictions. Such tracking systems contribute to the reduction of crime; terrorism and corruption. Consequently, all spheres of life are subjected to digitalization.

The digitalization of the state involves technological and economic transformation. Digitalization of the economy is not only electronic services; it is a whole system of economic relations that uses digital technologies.
The digitalization of the economy is a global process of the widespread introduction of digital technologies, which required in many countries of the world the rapid development of such technologies as information, microelectronic, and communication technologies. In the foreground were advanced production technologies, such as end-to-end information technology, neurotechnology, the Internet of things, and artificial intelligence [9].

The second approach to the consideration of the security of digital transformation notes the negative side of digital transformation, which is associated with the emergence of new threats to information security and the expansion of the range of vulnerabilities in the form of possible cyber-attacks, etc.

\section{RESEARCH RESULTS}

Information transformation is being replaced by digital transformation, which represents the main direction of scientific and technological progress and the basis of the future. It requires a complete modernization of the methods of running the economy, a revision of the internal processes of production, business, economy, the introduction of a new culture of relationships within industries and companies. This requires the emergence of new professions, and the modernization of old ones.

The most dangerous negative trend of digital transformation is the displacement of a person from society due to the accelerated release of unskilled labor, which will lead to an increase in unemployment in all countries. Digital transformation of the economy leads to social tension and political instability.

There are global challenges and threats to the development of modern society [10, 11]. Social challenges arise from job cuts, resulting in both social and economic instability.

The challenges of increasing the gap in the levels of technological development between countries and different economic groups lead to threats that contribute to the implementation of negative trends in the so-called "technological gap". The reason for its occurrence is the low technological level of the economy. Ineffective promotion of products to the world market, unequal exchange, inability to attract foreign investment contribute to the country's economy leading to a technological backwardness and falling into the trap of a "technological abyss", which contributes to undermining the country's national security.

Environmental risks are associated with the intensification of production, which can significantly change the climate. The possible threat requires the widespread creation and use of monitoring systems for ongoing technological changes, a "green economy", and waste-free technologies as protection for climate change. 
The risk of increased terrorism and the creation of new models of cyber weapons that do not require human participation in military operations, unequal access to the intellectual resources and confidential information pose threats to national security. Terrorism is dangerous for its all-encompassing destructive effect on all spheres of society. Terrorism as a challenge is dangerous not only for the population and the economy, but also for the political system of society, undermining the stability, authority and stability and citizens' faith in their state. Terrorism poses a threat to the use of weapons of mass destruction, which is associated with the greater availability of components of nuclear, chemical and biological weapons.

According to Klaus Schwab, who founded the World Economic Forum, the biggest public issue is inequality, leading to the digital revolution. Digital technologies lead to stagnation and lower incomes for the majority of the population.

Moreover, due to the concentration of most highly qualified personnel in economically developed countries, in other countries unskilled labor will be quickly released, which will significantly increase overt and hidden unemployment in almost all countries.

Another negative trend of our time is the instability of democratic institutions, which are under pressure from economic, cultural and technological changes. As a result, there is a weakening of the democratic system associated with the increasing tendencies of the population aging; creating environmental degradation; the protectionist sentiments of the governments of all countries are increasing; nationalist sentiments are growing; the balance of systems in public administration and interstate regulation is changing.

Digital transformation entails changing the way of people's lives. It is predicted that most of the job will take place at home, so there will be an outflow of population from cities and increased migration within and between countries. Education and professional development of employees will become permanent in order to meet the increasing requirements. At the same time, all areas of training will grow. Distance education will be the advantage.

The study of digitalization trends and identification of its dangers suggests that, on the one hand, it serves the interests of the formation of a post-industrial society. On the other hand, digitalization introduces a new world order, forms ideas about the instability of the digital society itself.

In order to be in demand in the future, it is necessary to study the professions of the future with the help of technological competence foresight now. The demand for representatives of digital professions has already grown by $885 \%$ over the past nine years. Experts believe that over 200 completely new professions will appear by
2030. Thus, the future is not connected only with one specific specialization, but in the ability to improve the most demanded thinking skills: cognitive flexibility, the ability to make decisions, the ability to coordinate with others to solve complex problems, critical thinking and creativity. In simpler jobs, a person will be replaced by a robot or another person whose labor will be cheaper.

Social stratification will occur due to the fact that the value of both low-skilled and medium-skilled labor decreases. It also creates an undermining of the material wealth of the large middle class. This is accompanied by the formation of global uncertainty, which contributes to the emergence of significant social unrest, and as a consequence of the emergence of fundamental changes in the structure of society.

Cyber-attacks disable critical important infrastructures and life support systems, which damages regions, states, and interstate structures. The escalation of cybercriminals activity around the world is intensifying in three directions [12]. The first area is related to the improvement of malicious software. These include ransomware viruses and system and data destruction programs, and others. Moreover, the self-distribution of software leads to the potential danger of the "fall" of the entire Internet and digital transformation.

Information security and information protection is now becoming increasingly important. This is due to the fact that information protection, having awareness of threats on the Internet, can ensure the confidentiality, availability and integrity of information and IT infrastructures [13].

Technological, engineering, organizational and other methods are used for information protection. Despite this, there are informational, financial losses and even human casualties. Cyberspace is filled with malicious software, and numerous Internet fraudsters, cybercriminals, and hackers spread their networks in it [14].

The security of a state is subject to its information structure from attacks by cyber units of other states, attacks by corporations, terrorist units, and individual citizens.

There are two main aspects of information security compliance at the level of interaction between the state, enterprises and individuals. On the one hand, the legitimate owners of the information should not experience difficulties when working with the data due to their privacy. On the other hand, only reliable protection can prevent and protect data from unauthorized use.

Ultimately, ensuring information security is the inadmissibility of any kind of damage at all levels. The primary task of information security is not to cause both material and moral damage to the user as a result of the distribution, modification or deletion of his data. 
In addition to the listed types of security, international security should be noted, which has the following levels: national, regional and global. International security invites all states to observe the principles and norms of international law that exclude the use of force or threat to resolve disputes and disagreements.

The current scale and scope of our life with digital technologies creates new military-political threats and geopolitical challenges. These include the use of information weapons for destructive purposes, terrorist activities, interference in the internal affairs of States, and unauthorized access to other people's information. Information threats can be compared with weapons of mass destruction in terms of their impact and their consequences.

It should be noted that the "Okinawa Charter for the Global Information Society" (Adopted on fr. Okinawa 22.07.2000) states that" the efforts of the international community aimed at the development of the global information society must be accompanied by concerted actions to create a secure and crime-free cyberspace." Over the years, as it was noted the threats and risks presented are not decrease, they increased to a threatening size [15]. Moreover, there is an opinion that at the present stage, information security cannot be ensured.

It should also be noted that the Internet is actually technically under the control of the private organization ICANN and the US government. And also recently the problem of Internet governance has become the most demanded one. This is due to the increasing complexity of the tasks of protecting citizens and information security of states whose information technologies are based on foreign developments. The "Strategy for the Development of the Information Society in the Russian Federation for 2017 - 2030" has a task for Russian companies to create breakthrough domestic technologies, and for the state - the task of ensuring and protecting their interests.

In our country the Strategy for the Development of the Information Society in the Russian Federation for 2017 - 2030 was approved in May 2017. Its tasks included the definition of goals, objectives, measures to implement the domestic and foreign policy of our country in the field of application of information and communication technologies. The focus of these technologies is due to the development of the information society, the formation of a national digital strategy, ensuring the interests of the nation and implementing the strategies of the nation's priorities.

\section{CONCLUSION}

Digital transformation is making a significant change in all areas, combining physical production and intelligent digital technology. An increase in the degree of digitalization of Russian industry, society, and the state, along with positive ones, can lead to negative economic and social events. Digitalization can cause negative socio-economic consequences, which, in turn, can lead to an increase in unemployment and increased inequality in the distribution of income.

The applied significance of the research is in the possibility of using the obtained conclusions to establish ideological, epistemological and methodological foundations for the development of digital transformation.

\section{REFERENCES}

[1] N. Morozova, O. Buryakova, N. Aliyeva, E. Ivushkina, Global information space: a non-linear approach. In: Lecture Notes in Networks and Systems, 57 (2019) pp. 236-240. DOI: https://doi.org/10.1007/978-3-030-00102-5_25.

[2] G. DiBona, V. Cesarotti, G. Arcese, T. Gallo, Implementation of Industry 4.0 technology: New opportunities and challenges for maintenance strategy. In: Procedia Computer Science, 180 (2021) pp. 424-429. DOI: https://doi.org/10.1016/j.procs.2021.01.258.

[3] E. Popkova, K. Zmiyak, Priorities of training of digital personnel for industry 4.0: social competencies vs technical competencies. In: On the Horizon, 27 (2019) pp. 138-144. DOI: https://doi.org/10.1108/OTH-08-2019-0058.

[4] O. Banerjee, N. Crossman, R. Vargas, L. Brander, P. Verburg, M. Cicowiez, J. Hauck, E. McKenzie, Global socio-economic impacts of changes in natural capital and ecosystem services: State of play and new modeling approaches. In: Ecosystem Services, 46 (2020) 101202. DOI: https://doi.org/10.1016/j.ecoser.2020.101202.

[5] N. Morozova, N. Aliyeva, O. Buryakova, Dangers and threats of the global digital space: a non-linear approach. In: Advances in Intelligent Systems and Computing, 1100 (2020) pp. 162-166. DOI: https://doi.org/10.1007/978-3-030-39319-9_18.

[6] N. Aliyeva, E. Ivushkina, N. Morozova, S. Vasenev, Human capital and identity in the global digital space. In: Advances in Intelligent Systems and Computing, 1100 (2020) pp. 156-161. DOI: https://doi.org/10.1007/978-3-030-39319-9_17.

[7] R. Aleshko, L. Petrova, E. Ivanova, A. Plotnikova, M. Melnikov, V. Antonov, Human capital in the digital economy format. In: International Journal of Engineering and Advanced Technology, 9 (2019) pp. 7517-7523. DOI: https://doi.org/10.35940/ijeat.A2201.109119. 
[8] V. Antonov, N. Atabekova, U. Pozdnyakova, A. Novikov, Digital Human: Principles of Behavior in the Market and Internal Contradictions. In: Lecture Notes in Networks and Systems, 87 (2020) pp. 161167. DOI: https://doi.org/10.1007/978-3-03029586-8_19.

[9] O. Ananova, Digital economy, the development ways of cryptocurrency. In: MATEC Web of Conferences, 226 (2018) 04050. DOI: https://doi.org/10.1051/matecconf/201822604050

[10] O. Grechenkova, Yu. Kuzmenko, Characteristics of certain crimes against peace and security of mankind as "essential threats" . In: Lecture Notes in Networks and Systems, 57 (2019) pp. 612-621. DOI: $\quad$ https://doi.org/10.1007/978-3-030-001025_64

[11] Y. Laniuk, Freedom in the Society of Control: Ethical challenges. In: Ethics and Bioethics (in Central Europe), 10 (2021) pp. 203-220. DOI: https://doi.org/10.2478/ebce-2020-0019.

[12] Z. Ariffin, Faris Hanif Ahmad, Indicators for maturity and readiness for digital forensic investigation in era of industrial revolution 4.0. In: Computers and Security, 105 (2021) 102237. DOI: https://doi.org/10.1016/j.cose.2021.102237.

[13] E. Ivushkina, N. Morozova, I. Kushnir, O. Buryakova, The internet as a synergetic model information interaction between chaos and order. In: Lecture Notes in Networks and Systems, 57 (2019) pp. 783-788. DOI: https://doi.org/10.1007/978-3030-00102-5_83.

[14] A. Malyuka, N. Miloslavskaya, Information Security and Expert's Knowledge Autoformalization. In: Procedia Computer Science, 88 (2016) pp. 288-293. DOI: https://doi.org/10.1016/j.procs.2016.07.437.

[15] Chun-YaoHuang, Rethinking leapfrogging in the end-user telecom market. In: Technological Forecasting and Social Change, 78 (2011) pp. 703712.

DOI: https://doi.org/10.1016/j.techfore.2010.10.009. 